\title{
Microstructure and mechanical performances of CGHAZ for oil tank steel during high heat input welding
}

\author{
Guo-Li Liang*, Shan-Wu Yang, Hui-Bin Wu, \\ Xue-Li Liu
}

Received: 10 September 2012/Revised: 28 September 2012/Accepted: 8 October 2012/Published online: 23 April 2013

(C) The Author(s) 2013. This article is published with open access at Springerlink.com

\begin{abstract}
Microstructure and mechanical performances of the coarse grain heat-affected-zone (CGHAZ) for oil tank steel with different $\mathrm{Ti}$ content were investigated through Gleeble-3500, scanning electron microscopy, transmission electron microscopy, and energy dispersive spectrometer. The results show that the strength and lowtemperature toughness of base material are significantly improved for the high titanium content steel, but the impact toughness of CGHAZ is seriously deteriorated after the high heat input welding and declined sharply with the heat input increasing, while the effects of heat input on impact toughness are very weak for the low titanium content steel, impact toughness of which is gradually larger than that of high titanium content steel with the welding heat input increasing because of the granular bainite increasing, TiN particle coarsening, and ( $\mathrm{Ti}, \mathrm{Nb}$ ) $\mathrm{N}$ composition evolution during the high input welding for high titanium content steel.
\end{abstract}

Keywords Ti-steel; CGHAZ; Impact toughness; TiN particle

G.-L. Liang*, S.-W. Yang

Department of Material Physics and Chemistry, University of Science Technology of Beijing, Beijing 100083, China e-mail: guoliliang428@163.com

G.-L. Liang, H.-B. Wu, X.-L. Liu

National Engineering Research Center for Advanced Rolling

Technology, University of Science Technology of Beijing,

Beijing 100083, China

G.-L. Liang

Department of Electro-Mechanical Engineering,

Tangshan College, Tangshan 063000, China

\section{Introduction}

High-strength low-alloy steel has been widely applied to build the large-scale structures, such as oil tank, because it has a huge volume up to $10-20$ million $\mathrm{m}^{3}$, wherein a lot of welding works are required in the construction [1-3]. In order to save cost and improve construction and efficiency, high efficient automatic welding methods, such as submerged arc welding and electro-gas arc welding, must be employed. However, the high heat input welding tends to cause a considerable reduction in the strength and toughness of HAZ, especially for the coarse grain heat-affected-zone (CGHAZ). The CGHAZ is adjacent to the fusion line, where the peak temperature is close to the melting point of steel, which results in austenite grain obviously coarsening and occurrence of coarse grained embrittlement. Meanwhile, the continuous rapid cooling after the peak temperature also spurs the formation of upper bainite and granular bainite, resulting in microstructure brittleness [4-6].

The toughness of CGHAZ is significantly improved by adding $\mathrm{Ti}, \mathrm{Nb}$, and other microalloyed elements in the lowalloy high strength steel; this is because of the action between $\mathrm{Ti}, \mathrm{Nb}$, and $\mathrm{C}, \mathrm{N}$ in the steel to form the fine dispersed carbonitride. These carbonitrides block the growth of austenite grains and improve the secondary microstructure of CGHAZ. However, these second-phase particles dissolve, grow, and reprecipitate when they experience the welding thermal cycle; the size, number, and distribution of the second particles are affected in the welding process, and then, the ability to block austenite grain growth and the toughness of CGHAZ are also affected [7, 8]. Therefore, it is very important for us to study the effects of Ti content on the high-strength oil tank steel when they experience the high heat input welding. At present study, the impact toughness and hardness of steel 
with different Ti content in the welding thermal cycle were investigated by metallographic microscope, scanning electron microscopy (SEM), and transmission electron microscope (TEM).

\section{Experimental}

\subsection{Materials}

Experimental steel is $690 \mathrm{MPa}$ grade oil tank steel developed by our laboratory, whose chemical compositions are shown in Table 1. A stands for low titanium content steel, and B stands for high titanium content steel; the ingot was quenched offline and tempered after controlled rolling and cooling, whose mechanical properties all meet the requirements of $690 \mathrm{MPa}$ grade oil tanks steel. The $R m$ of A steel is $725 \mathrm{MPa}, R c l=640 \mathrm{MPa}$, and the $R m$ of B steel is $820 \mathrm{MPa}, R c l=780 \mathrm{MPa}$.

\subsection{Methods}

The welding heat cycle of CGHAZ was simulated by Gleeble-3500 thermal simulation testing machine. The sample was made laterally with $10 \mathrm{~mm} \times 10 \mathrm{~mm} \times$ $55 \mathrm{~mm}$; the notch was opened at the center of solder joint connected by a thermocouple; and then, the impact test as the Charpy V-notch was carried out. The heating rate is $130\left(^{\circ}\right) \cdot \mathrm{s}^{-1}$ during simulation of the thermal cycling, peak temperature $\left(T_{\mathrm{p}}\right)$ is $1,320^{\circ} \mathrm{C}$, the delay time of peak temperature was $1 \mathrm{~s}$, and cooling time from 800 to $500^{\circ} \mathrm{C}\left(T_{8 / 5}\right)$ is respectively 15,36 , and $46 \mathrm{~s}$ corresponding to the welding heat input with 30,50 , and $80 \mathrm{~kJ} \cdot \mathrm{cm}^{-1}$.

The thermal simulated samples were corroded with $4 \%$ nitric acid alcohol solution after grinding, polishing, and the microstructures were observed by optical microscopy and field emission SEM. The extraction replica samples were made by speed method for TEM observation. The size, morphology, and distribution of the second-phase particles were observed in JEM-2000 transmission electron microscope. Meanwhile, the $400 \mu \mathrm{m}$ thin slices were cut from the center of solder joint connected the thermocouple; the $\Phi 3 \mathrm{~mm}$ backlash was made after grinding to $80 \mu \mathrm{m}$; then the electrolytic double jet test of samples was carried out in $5 \%$ perchloric acid $+95 \%$ ethanol solution, and the fine microstructures were observed in TEM. The hardness was measured in Vickers-hardness with $10 \mathrm{~kg}$ load, and then, the average value after multipoint measurement was obtained.

\section{Results and discussion}

3.1 Low-temperature impact toughness and hardness of base materials and CGHAZ

Figure 1 shows the impact toughness and hardness experienced different welding heat input, where zero heat

Table 1 Chemical compositions of test steel (wt\%)

\begin{tabular}{|c|c|c|c|c|c|c|c|c|c|c|c|}
\hline Type & $\mathrm{C}$ & $\mathrm{Si}$ & $\mathrm{Mn}$ & $\mathrm{P}$ & S & $\mathrm{Ni}+\mathrm{Cr}+\mathrm{Mo}$ & V & $\mathrm{Ti}$ & $\mathrm{Nb}$ & $\mathrm{N}\left(10^{-4}\right)$ & $\mathrm{P}_{\mathrm{cm}}$ \\
\hline A & 0.09 & 0.28 & 1.3 & 0.006 & 0.006 & $<0.9$ & 0.04 & 0.018 & 0.03 & 38 & 0.20 \\
\hline B & 0.09 & 0.30 & 1.3 & 0.006 & 0.006 & $<0.9$ & 0.05 & 0.089 & 0.03 & 46 & 0.21 \\
\hline
\end{tabular}

$\mathrm{P}_{\mathrm{cm}}=\mathrm{C}+\mathrm{Si} / 30+(\mathrm{Mn}+\mathrm{Cu}+\mathrm{Cr}) / 20+\mathrm{Ni} / 60+\mathrm{Mo} / 15+\mathrm{V} / 10+5 \mathrm{~B}$
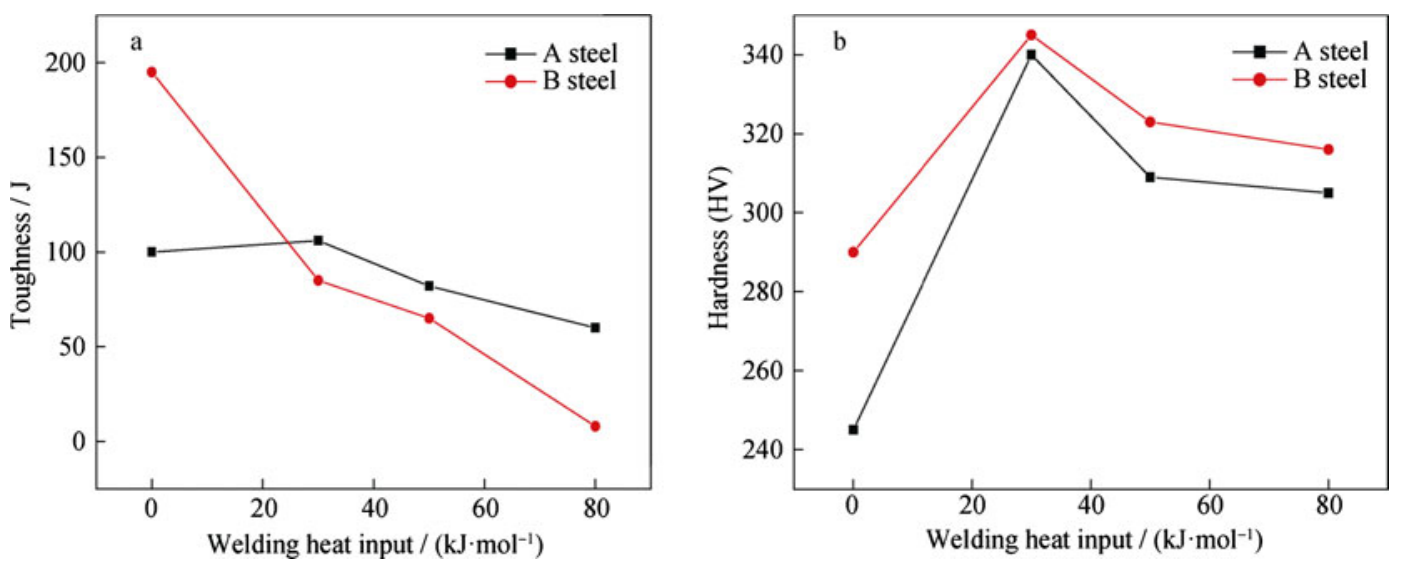

Fig. 1 Hardness and impact toughness of CGHAZ in different welding heat input a toughness of CGHAZ and base metal, and $\mathbf{b}$ hardness of CGHAZ and base metal 
input represents the base metal. The impact toughness of base metal for high titanium content steel (B steel) is $87 \mathrm{~J}$ higher than that of low titanium content steel (A steel), as shown in Fig. 1a, but with the heat input increasing, the toughness of both A steel and B steel all decreases. When the welding heat input reaches $80 \mathrm{~kJ} \cdot \mathrm{cm}^{-1}$, the low-temperature impact toughness of high titanium content steel was only $18 \mathrm{~J}$, and the toughness deteriorates sharply.

The hardness of both A steel and B steel are all higher than that of base metal experienced welding heat cycle, and both hardness ascends at first and then descends last, as shown in Fig. 1b; it is because the austenite transforms to the lath bainite and granular bainite under the continuous cooling conditions. The amount of granular bainite increases and the amount of lath bainite decreases with the cooling time increasing from 800 to $500{ }^{\circ} \mathrm{C}\left(T_{8 / 5}\right)$, which leads to the hardness and toughness of CGHAZ gradually decreasing [9].

\subsection{Effects of welding heat input on microstructures of CGHAZ}

Figure 2a shows the microstructures of base metal for the low titanium content steel (A steel), which is made up of the tempered bainite and a small amount of ferrite. The welding thermal simulation test are carried out by Gleeble3500 for base metal; when the welding heat input is
$30 \mathrm{~kJ} \cdot \mathrm{cm}^{-1}$, the microstructures of CGHAZ are mainly made up of the lath bainite and a small amount of granular bainite, as shown in Fig. 2b. This kind of hybrid microstructure insures that the CGHAZ of the low titanium content steel has high hardness and toughness after welding heat cycle. In addition, the intragranular acicular ferrite is found in CGHAZ, as shown in Fig. 3a, and it is for another reason that the toughness of CGHAZ is higher than that of base metal for low titanium content steel. When the welding heat input is $50 \mathrm{~kJ} \cdot \mathrm{cm}^{-1}$, the microstructures of CGHAZ are mainly made up of the lath bainite, but the granular bainite increases, and the original austenite grain grows, as shown in Fig. 2c, and the toughness of CGHAZ begins to decline. When the welding heat input reaches $80 \mathrm{~kJ} \cdot \mathrm{cm}^{-1}$, the microstructure of CGHAZ are mainly made up of the upper bainite and the original austenite grain grows up markedly; the lath of bainite and ferrite coarsens, and the toughness of CGHAZ declines significantly, as shown in Fig. 2d.

Figure 2e shows the microstructures of base metal for the high titanium content steel (B steel), which is mainly made up of the typical tempered bainite. When the welding heat input is $30 \mathrm{~kJ} \cdot \mathrm{cm}^{-1}$, the microstructures of CGHAZ are mainly made up of the lath bainite together with a small amount of granular bainite, as shown in Fig. 2f; this kind of microstructure insures that the CGHAZ of the high titanium content steel has high hardness and toughness after welding. When the welding heat input is $50 \mathrm{~kJ} \cdot \mathrm{cm}^{-1}$, the
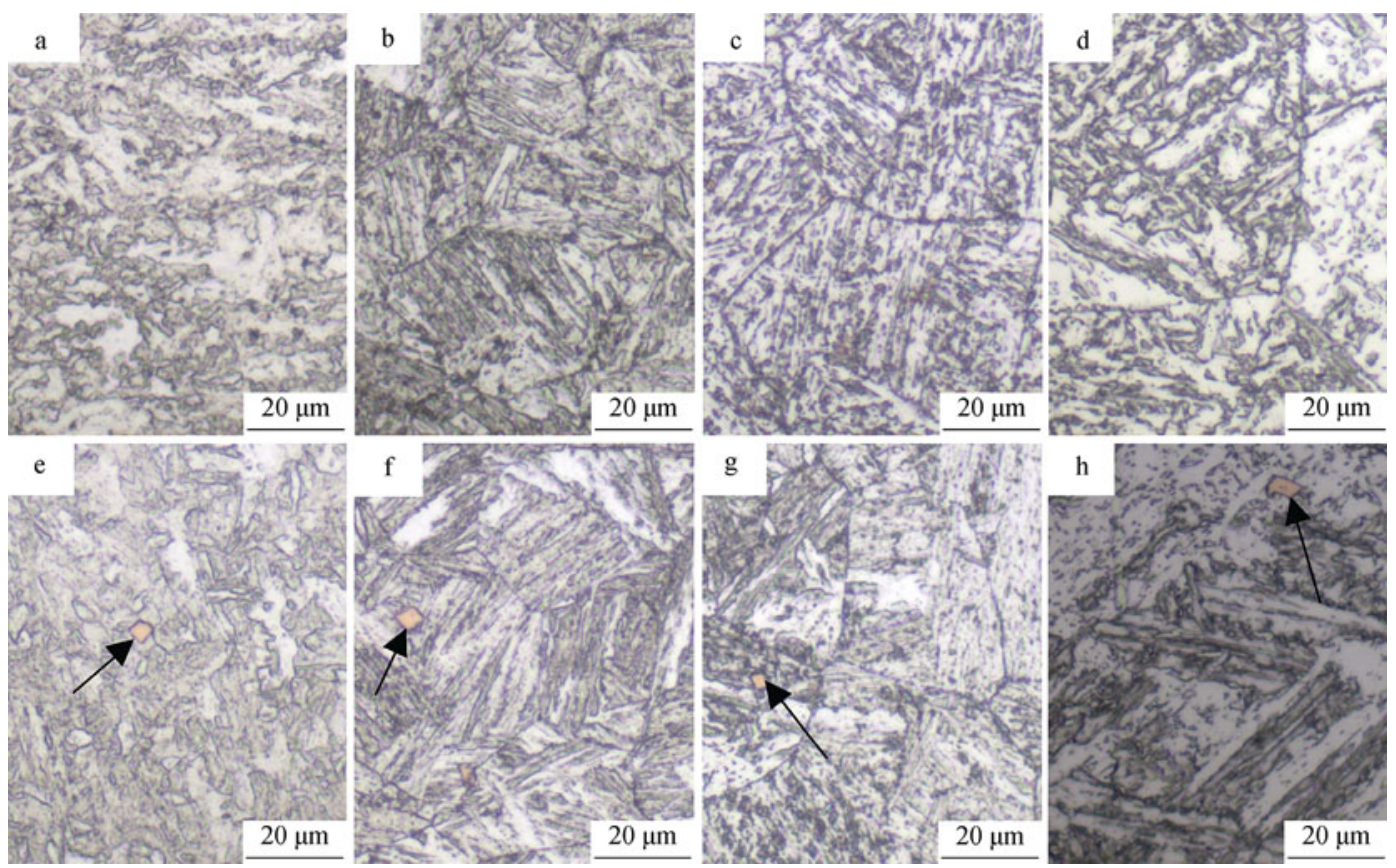

Fig. 2 SEM images of base metal and CGHAZ in different welding heat input: a base metal of A steel, b $30 \mathrm{~kJ} \cdot \mathrm{cm}^{-1}$ of A steel, c $50 \mathrm{~kJ} \cdot \mathrm{cm}^{-1}$ of A steel, d $80 \mathrm{~kJ} \cdot \mathrm{cm}^{-1}$ of A steel, e base of metal of B steel, $\mathbf{f} 30 \mathrm{~kJ} \cdot \mathrm{cm}^{-1}$ of B steel, $\mathbf{g} 50 \mathrm{~kJ} \cdot \mathrm{cm}^{-1}$ of B steel, and h $80 \mathrm{~kJ} \cdot \mathrm{cm}^{-1}$ of B steel 
microstructures of CGHAZ are mainly composed of the lath bainite, but the granular bainite increases, and the original austenite grain grows up, as shown in Fig. $2 \mathrm{~g}$, and the toughness decreases obviously. When the welding heat input reaches $80 \mathrm{~kJ} \cdot \mathrm{cm}^{-1}$, the microstructures of CGHAZ are mainly composed of the upper bainite, the grain boundaries of original austenite become blurry, as shown in Fig. $2 \mathrm{~h}$; the toughness of CGHAZ is seriously deteriorated to only $8 \mathrm{~J}$.

Further observation by TEM, when the welding heat input is $50 \mathrm{~kJ} \cdot \mathrm{cm}^{-1}$, it is found that the grain size of CGHAZ for low titanium content steel (A steel) is reduced by the action of intragranular acicular ferrite, as shown in Fig. 3a, while the coarse M-A island component is found in CGHAZ for high titanium content steel (B steel), as shown in Fig. 3b. It was reported [10] when the average chord lengths of the M-A island component were larger than $2 \mu \mathrm{m}$, the critical size of Griffith crack was formed. The volume fraction of M-A island component and the average chord lengths of CGHAZ are further measured for the high titanium content steel, and it is found that the amount of M-A island component and the average chord lengths of CGHAZ increase with the welding heat input increasing for the high titanium content steel, which results in the impact toughness of low-temperature declining seriously.

\subsection{Effects of inclusions and the second phase particles in CGHAZ}

The trace alloy element additive causes the formation of the high melting point particles that appear to diffuse [11, 12]; these particles on one hand pin the austenite grain boundary to block the austenite grain boundary migration and limit the austenitic grain growth up, and on the other hand, they increase the nucleation point of phase transformation to get the finer microstructure $[13,14]$. Adding $\mathrm{Ti}, \mathrm{Nb}$ micro alloy

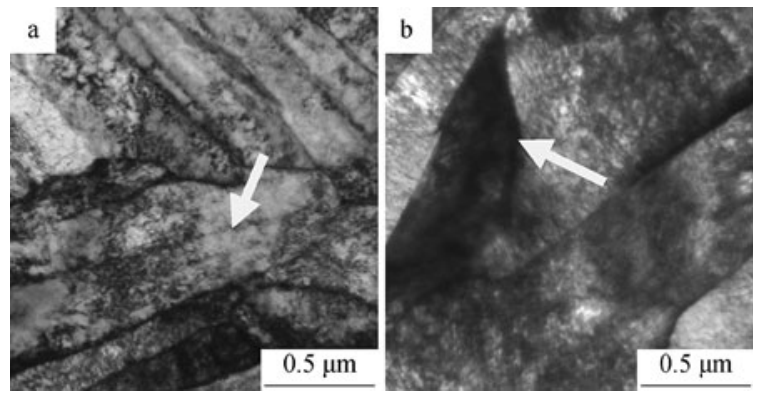

Fig. 3 TEM images of CGHAZ: a $50 \mathrm{~kJ} \cdot \mathrm{cm}^{-1}$ of A steel and b $50 \mathrm{~kJ} \cdot \mathrm{cm}^{-1}$ of B steel elements to the steel can form carbonitride particles to block the austenitic grain growth up, affect the microstructure of the weld and heat-affected zone, and improve the performance of joints $[15,16]$. The smaller the particle size is, the greater the action to block austenitic grain growth is. At present study, the effects of different titanium content on the performance of CGHAZ were investigated.

The arrows in Fig. 2e-h showed the square inclusions with $2-5 \mu \mathrm{m}$ in the base metal and CGHAZ for the high titanium content steel, and they are mainly made up of $\mathrm{Nb}$ nitride or $\mathrm{Ti}$ nitride by energy dispersive spectrometer (EDS) analysis. However, the ratio of $\mathrm{Ti}$ to $\mathrm{N}$ is too large for the high titanium content steel (B steel); the coarse TiN particles are precipitated in the solidification; the coarse TiN particles cannot block effectively the austenite grain growth. This is one of factors why the impact toughness of CGHAZ is seriously deteriorated after high heat input welding and declines sharply with the increase in heat input.

The extraction replica samples are observed by TEM. It is found that there are a large number of fine precipitated particles that disperse in matrix after welding, and the morphologies present the regular rectangular and cube, as shown in Fig. 4. The precipitated second particles all contain $\mathrm{Ti}$ and $\mathrm{Nb}$ element in the low titanium content steel (A steel) and high titanium content steel (B steel), they are the Ti nitride or $\mathrm{Nb}$ nitride. EDS analysis indicates that the average content of the (Ti,Nb)N particles is $73 \% \mathrm{Ti}$ and $27 \% \mathrm{Nb}$ in high titanium content steel, while the average content of the (Ti,Nb) N particles is $55 \% \mathrm{Ti}$ and $45 \% \mathrm{Nb}$ in low titanium content steel. It is found that the higher the content of $\mathrm{Ti}$ in second particle $(\mathrm{Ti}, \mathrm{Nb}) \mathrm{N}$ is, the worse the toughness of CGHAZ is.

\section{Conclusion}

At present study, the effects of different titanium content on the microstructures and performances of CGHAZ were investigated, and the low-temperature toughness of CGHAZ for low titanium content steel developed by our laboratory still meets the performance requirement when the welding heat input reaches $80 \mathrm{~kJ} \cdot \mathrm{cm}^{-1}$. Trace alloy element $\mathrm{Ti}$ additive improves the strength and toughness of steel, but have no contribution to the $\mathrm{P}_{\mathrm{cm}}$ (Carbon equivalent), too much Ti significantly decrease the mechanical properties in the welding process. Meanwhile, with the increase of Ti content, the composition of second particles $(\mathrm{Ti}, \mathrm{Nb}) \mathrm{N}$ occurs and significantly changes from $55 \% \mathrm{Ti}$ to $73 \% \mathrm{Ti}$, the precipitations increase and coarsen in high heat input welding, and the impact toughness of low temperature also decreases rapidly. 

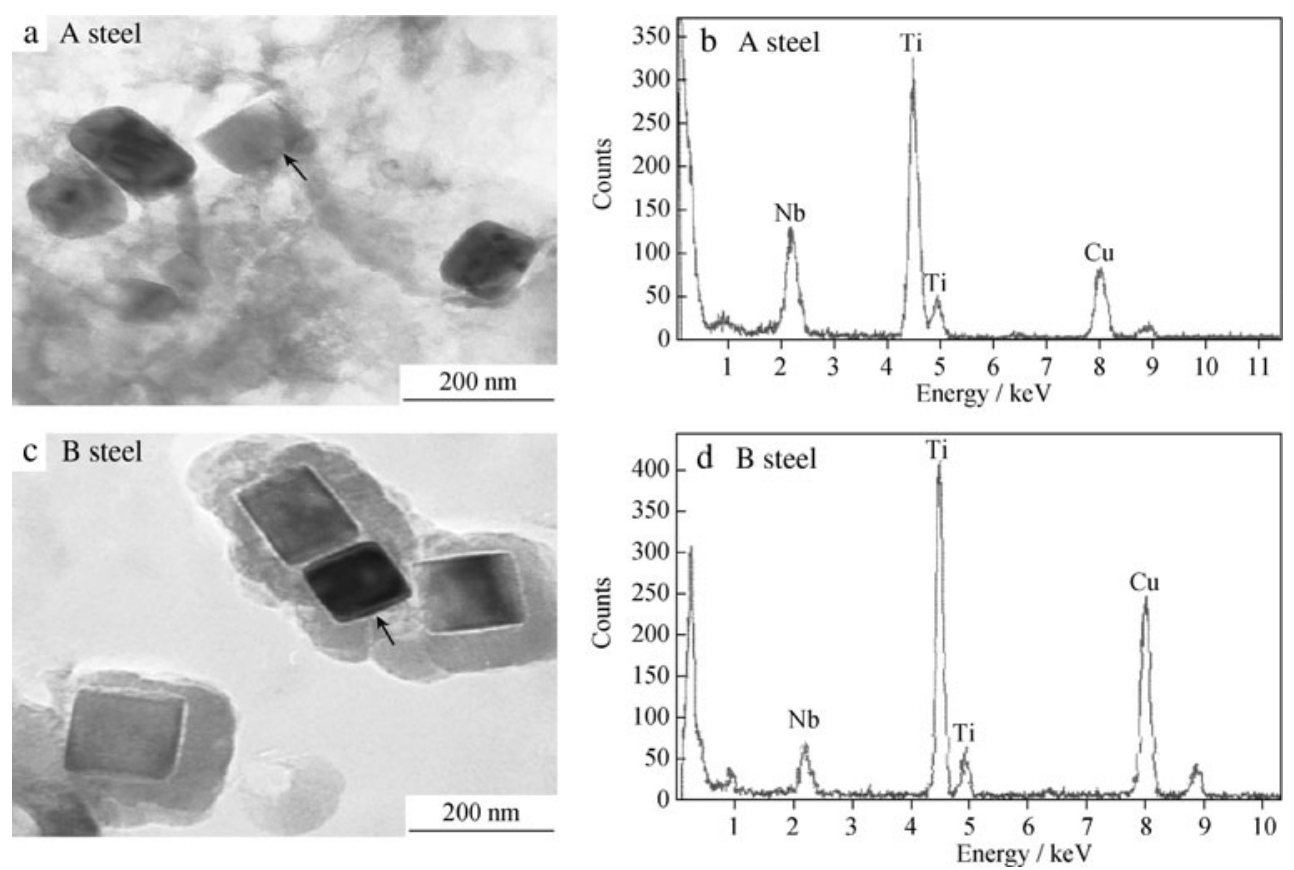

Fig. 4 TEM images and EDS analysis of second-phase particles in CGHAZ: a the second-phase particles of A steel in CGHAZ, b EDS analysis of A steel, $\mathbf{c}$ the second-phase particles of B steel in CGHAZ, and $\mathbf{d}$ EDS analysis of B steel

Acknowledgments This study was financially supported by the Fundamental Research Funds for the National Science and Technology Support Program (No. 2011BAE25B01).

Open Access This article is distributed under the terms of the Creative Commons Attribution License which permits any use, distribution, and reproduction in any medium, provided the original author(s) and the source are credited.

\section{References}

[1] Ji WM. The synthetical application of high effective welding technology in $1.0 \times 10^{5} \mathrm{~m}^{3}$ oil tank construction. Petro Eng Constr. 2000;26(6): 16 .

[2] Wang M. Effect of weld thermal cycle on second phase particles in Ti-Nb micro-alloy steel. Hot Working Tech. 2009;38(21):22.

[3] Easterling KE. Introduction to the physical metallurgy of welding. In: Easterling KE, editor, Oxford: ButterworthHeinemann, 1983:17.

[4] Yamamoto K. Effect of boron on intra-granular ferrite formation in Ti-oxide bearing steels. ISIJ Int. 1996;36(1):80.

[5] Farrar RA, Harrison PL. Acicular ferrite in carbon-manganese weld metals: an overview. J Mater Sci. 1987;22:3812.

[6] Kojima A. Super high HAZ toughness technology with fine microstructure imparted by fine particles. Nippon Steel Bull. 2004;380:225.

[7] Terada Y, Tamehiro H, Morimoto,H. Hara T, Tsuru E. X100 line-pipe with excellent HAZ toughness and deformability. In: Proceedings of OMAE - 22nd International Conference on
Offshore Mechanics and Arctic Engineering, Cancun. 2003; 6:287.

[8] Nagai Y, Fukami H, Inoue H, Nakashima T, Kojima A. Production of high-toughness steel for offshore structures. In: Proceedings of OMAE - 22nd International Conference on Offshore Mechanics and Arctic Engineering, Cancun. 2003;6:319.

[9] Yan HC, Cao HQ, Luo D, Li GM, Xia ZH, Liu JQ. Influence of $\mathrm{Ti}, \mathrm{Nb}$ and $\mathrm{B}$ on microstructure and mechanical properties of low carbon bainitic steel. J Iron Steel Res. 2010;22(5):55.

[10] Lee S, Kim BC, Kwon D. Fracture toughness analysis of heataffected zones in high-strength low-alloyed steel weld. Metall Mater Trans A. 1993;24(5):1133.

[11] Oñoro J. High-temperature mechanical properties of aluminium alloys reinforced with titanium diboride (TiB2) particles. Rare Met. 2011;30(2):200.

[12] Ying XY, Xiong J, Guo ZY, Chen JZ. Effect of VC addition on the microstructure and properties of $\operatorname{Ti}(\mathrm{C}, \mathrm{N})$-based nano cermets. Rare Met. 2011;30(6):583.

[13] Chen MA, Wu CS, Wang JG, Tang YM, Luo SN. Effect of second phase particle on microstructure and toughness of CGHAZ in HSLA. Trans China Welding Inst. 2002;23(3):37.

[14] Lee JL, Pan YT. Microstructure and toughness of the simulated $\mathrm{HAZ}$ in $\mathrm{Ti}$ and $\mathrm{Al}$ killed steels. Mater Sci Enger. 1991;A136(2):109.

[15] Stride J, Easterling KE. On the chemistry and stability of complex carbides and nitride in microalloyed steels. Acta Metall. 1985;33(11):2057.

[16] Gao JS, Hong YC, Wu HY, Yin GQ. Study on growth of austenite grain in microalloy steel welding HAZ. Iron Steel Vanadium Titanium. 1996;17(1):8. 